\title{
Dialogue between Midwives and Parents-to-Be about Alcohol, from a Life Cycle Perspective-An Intervention Study
}

\author{
Hjördis Högberg ${ }^{*}$, Fredrik Spak ${ }^{2}$, Margareta Larsson' ${ }^{1}$ \\ ${ }^{1}$ Department of Women's and Children's Health, Uppsala University, Uppsala, Sweden \\ ${ }^{2}$ Social Medicine, University of Gothenburg, Göteborg, Sweden \\ Email: hjordis.hogberg@kbh.uu.se, Fredrik.Spak@socmed.gu.se, Margareta.Larsson@kbh.uu.se
}

Received 13 December 2014; accepted 1 April 2015; published 3 April 2015

Copyright (C) 2015 by authors and Scientific Research Publishing Inc.

This work is licensed under the Creative Commons Attribution International License (CC BY). http://creativecommons.org/licenses/by/4.0/

\section{Abstract}

The objective was to investigate the use of alcohol during pregnancy among parents-to-be and to develop and evaluate a method for a dialogue about alcohol from a life cycle perspective. The study was a quasi-experiment. An intervention group (IG) with 238 couples and a comparison group (CG) with 271 couples participated. All of the participants were recruited at public antenatal care clinics (ANC) in Sweden. At registration, the midwife had a dialogue about alcohol with the IG, and the intervention was evaluated using questionnaires in pregnancy weeks 12 and 33. Alcohol consumption, alcoholism in the family, social support, and source of information were measured. More than $\mathbf{9 1 \%}$ of all pregnant women reported that they never drank alcohol either at registration or late in pregnancy, with no difference between the intervention group and the comparison group. Their male partners had a different pattern; $6 \%$ abstained from alcohol and about half of them drank alcohol two to four times a month. Nine percent of the participants had experienced an alcohol-dependent parent and $35 \%$ of the couples reported alcoholism in either of their families. Most women (92\%) stated that the partner's support to give up alcohol was important. After the intervention, more women in the IG were offered alcohol-free alternatives. About $40 \%$ of the partners had reduced their alcohol consumption; they received less social support for alcohol reduction than the pregnant women. A majority, $68 \%$, of the women in the IG stated ANC as the most important source of information about alcohol and pregnancy, compared to $53 \%$ in the CG $(p<0.001)$. After the intervention, a higher proportion of women in the IG were offered alcohol-free alternatives and ANC became the most important source of information about alcohol. Involving the partner in counseling about alcohol-restriction during pregnancy may be a useful health promotion strategy.

\section{Keywords}

Alcohol, Intervention, Pregnancy, Partner, Social Support

\footnotetext{
${ }^{*}$ Corresponding author.
}

How to cite this paper: Högberg, H., Spak, F., \& Larsson, M. (2015). Dialogue between Midwives and Parents-to-Be about Alcohol, from a Life Cycle Perspective-An Intervention Study. Creative Education, 6, 489-500. 


\section{Introduction}

Becoming a parent is a time of change and reorientation in life. For many, the pregnancy period is a natural continuation and a deepening of the relationship, providing the opportunity to reflect and mature, looking back at the cultural identity of both parents-to-be, and looking forward to joint parenthood (Dunkel-Schetter, Sagrestano, Feldman, \& Killings Worth, 1996). In the Life Event Theory, it has been emphasized that pregnancy can cause stress, which some couples find difficult to handle. Parents-to-be who support one another emotionally and practically, and those who receive psychosocial support from family and friends are better equipped for the maintenance of health, and interaction can improve patient health by improving the individual's self-understanding (Ogden, 2000).

Alcohol affects the overall health and is, therefore, important from a public health perspective. After tobacco and high blood pressure, alcohol is the third largest risk factor for men (and seventh largest risk factor for women) for mortality and premature death in developed countries. Only half the world's population drinks alcohol, but alcohol is the third leading cause of ill health and premature death globally, after low birth weight and unsafe sex, and greater than tobacco (World Health Organization, Regional Office for Europe, 2012).

The alcohol consumption in Sweden increased from 3 - 6 liters per person per year in the 1960s to around 8 liters per year in 1996. The consumption increased further with 30 percent between 1996 and 2004, to 10.4 liters and decreased thereafter to some extent to the most recent figure, which is 9.1 liters per person per year in 2013. During this entire period, there has been a gradual reduction of the gender difference in the consumption levels, and also in the alcohol related mortality (Holmqvist \& Nilsen, 2010). But still there is a three and a half time higher rate for men (CAN, 2014).

In the early seventies, a Fetal Alcohol Syndrome was described in the US (Jones \& Smith, 1973). There are however conflicting results regarding the effects of light or moderate drinking during pregnancy (Black, 2007; Göransson, 2004; Henderson, Gray, \& Brocklehurst, 2007; Sayal, 2007). Recent studies show effects of prenatal alcohol exposure later in life (Coles et al., 2011; Day, Helsel, Sonon, \& Goldschmidt, 2013).

The environment in which the child grows up is an important determinant of the child's future health. Motherhood as well as fatherhood can be a reason for changing alcohol consumption (Boyce, Condon, Barton, \& Corkindale, 2007; Genesoni \& Tallandini, 2009; Hyssälä, 1992). If there is a genetic disposition for Alcohol Disorder in the family, there is $>40 \%$ risk of developing an Alcohol Disorder during lifetime (Sullivan, Daly, \& O’Donovan, 2012). Many children of alcohol dependent parents have done well, but others have had difficulties during childhood and need extra support in their own parenting (Weitzman \& Wechsler, 2000).

In Sweden, midwives provide antenatal care based on a seven to eight visit basic program, and the midwife is responsible for the care in a normal pregnancy. Caring for women and partners includes medical care, psychosocial support, and health promotion; moreover, many midwives in Sweden have received training in Motivational Interviewing (MI). In pregnancy week 6 - 7, all pregnant women/couples are invited to one first visit focused on health and lifestyle. The midwife hands out a booklet about pregnancy and alcohol. However, the booklet does not provide any information regarding alcohol consumption, for the partner, prior to pregnancy and in parenting. All pregnant women are screened for current alcohol consumption and alcohol intake during the last year before the pregnancy with the Alcohol Use Disorder Identification Test (AUDIT) form. AUDIT contains ten questions about consumption of alcohol ( 0 - 40 points) during the last year before pregnancy. If a pregnant woman is still drinking alcohol at time for the health talk and the score is higher than 9 points she will be referred to a special counseling team (Göransson, 2004; Saunders, 1993; Skagerström, Johansson, Holmqvist, Envall, \& Nilsen, 2012).

More pregnant women, who receive both information and intervention, reduce their alcohol consumption than those receiving only information. This was shown in a study with a brief intervention consisting of: 1) knowledge assessment and feedback; 2) contracting and goal setting; 3) behavioral modification; and 4) summary (Chang, Wilkins-Haug, Berman, \& Goetz, 1999). In a later study they showed that the effects of a brief intervention (25 minutes) were enhanced when a partner participated together with the pregnant woman (Chang, McNamara, Orav, \& Wilkins-Haug, 2006). Various studies show that pregnant women drink less when they have knowledge about how alcohol can damage the child; moreover, they also find it easier to refrain from alcohol if those around them also drink less and provide emotional support (Aaronson, 1989; Abela, 2000). Only a few studies have investigated the relationship between psychosocial support from the partner and alcohol consumption during pregnancy, and only one intervention study involved both parents-to-be (Austin, Priest, \& Sul- 
livan, 2008; Chang, McNamara, Orav, \& Wilkins-Haug, 2006; Harrison, Godecker, \& Sidebottom, 2011; Mellingen, Torsheim, \& Thuen, 2013; Skagerstrom, Chang, \& Nilsen, 2011; van der Wulp, 2014).

The purpose of this study was to investigate the use of alcohol during pregnancy among both parents-to-be and to develop and evaluate a method for the midwife's dialogue about alcohol from a life cycle perspective with all parents-to-be during pregnancy.

\section{Method}

The study was a quasi-experimental intervention study within the regular ANC-activities. All data were collected from 2002-12-01 to 2004-05-31. The study invited the parents-to-be from the public ANC clinics in three counties in Sweden. The intervention group came from one county and the control group came from two other counties. Altogether, ten midwives working at three different ANC clinics provided the intervention. All midwives volunteered to be part of the study and received information about the study protocol. Those who were to provide the intervention were educated about the different steps, and the midwives who recruited the comparison group were instructed to provide care as usual. Prior to the study, the project leader had several meetings with the midwives and she also provided supervision throughout the study to ensure compliance with the study protocol. All Swedish speaking pregnant women who had a partner at the time of the registration were invited to participate.

The intervention group (IG) consisted of 297 couples, out of whom 219 (74\%) couples responded to the baseline questionnaire. Of these, 173 couples responded at post-measurement (79\%). The comparison group (CG) consisted of 383 couples out of which 266 couples responded to the baseline questionnaire (69\%). Of these, 202 (76\%) couples responded at post-measurement. At the registration visit, $64.6 \%$ of the partners in the IG participated, compared to $48.3 \%$ in the CG (Figure 1 ).

The intervention group received information about the study and a booklet about pregnancy and alcohol, which was mailed to their residence. They were requested to fill in a short questionnaire when they came to the ANC (Figure 2). In addition to the standard care, this group was exposed to the intervention; specifically, they were offered a dialogue about alcohol from a life cycle perspective with the midwife (Figure 3). The intervention took its starting point from the data that both partners provided regarding: alcohol consumption in the year prior to pregnancy, alcoholism in their family or within the family, with whom they drank, alcohol consumption

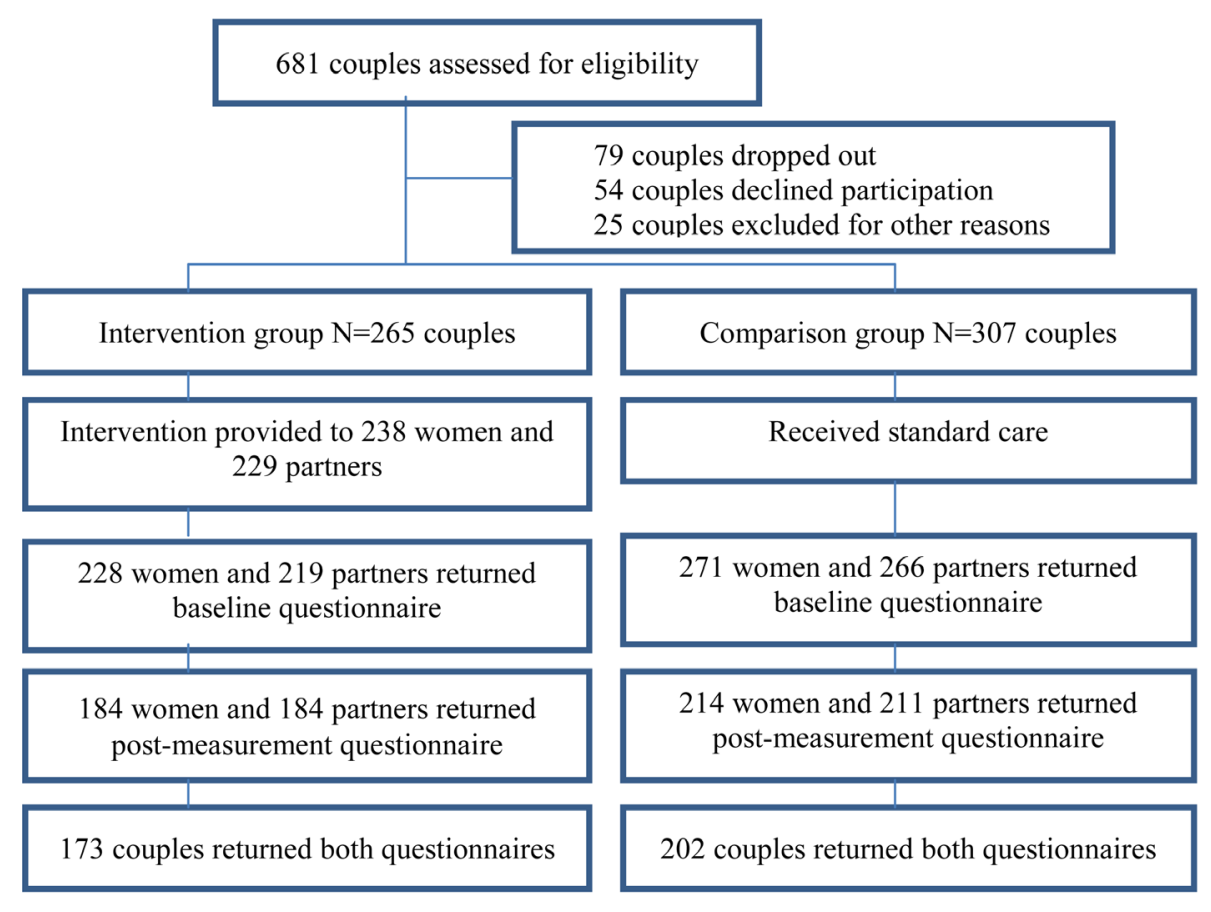

Figure 1. Flow chart of the participants. 


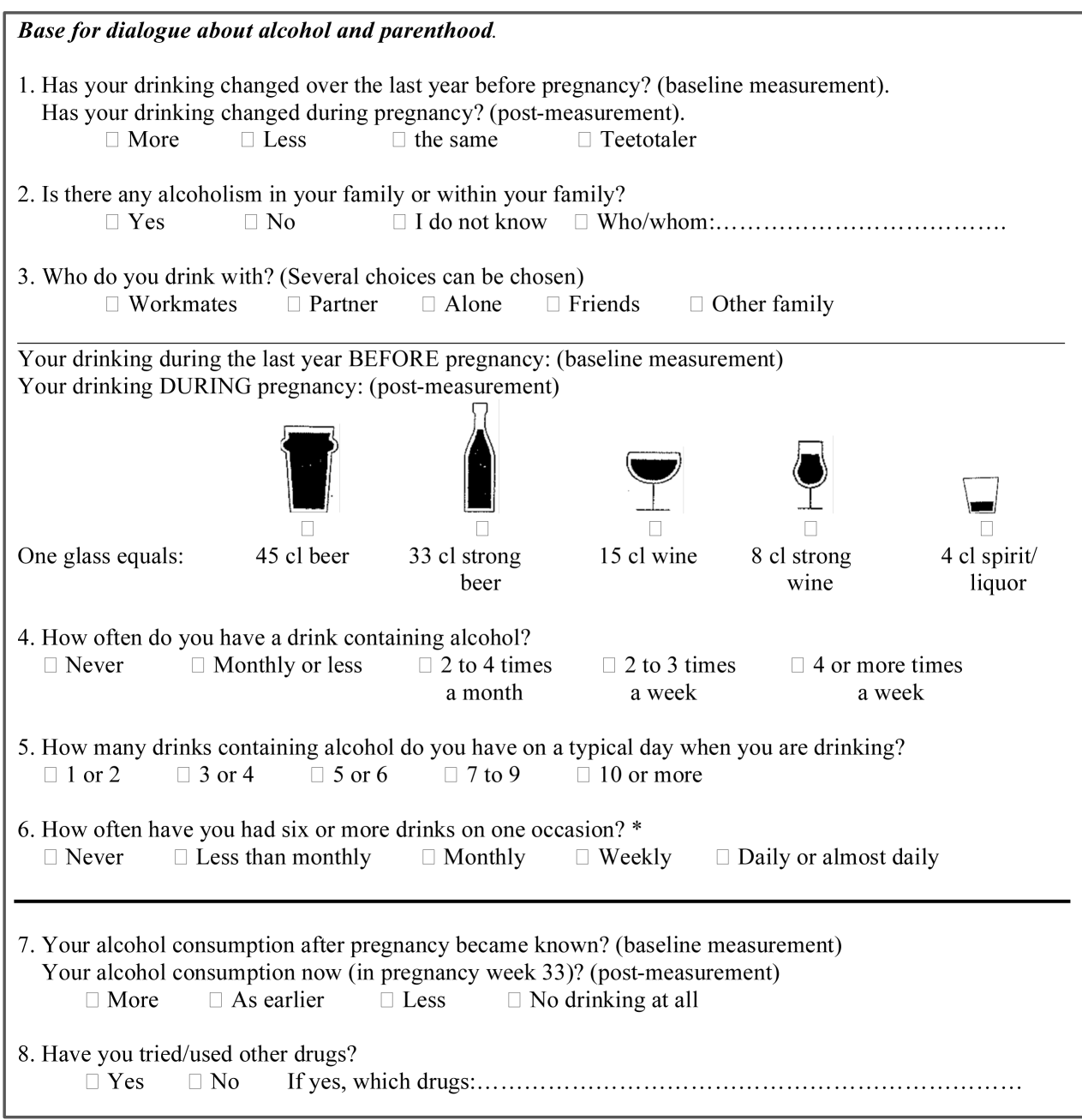

Figure 2. Base for dialogue about alcohol and parenthood. *Four or more drinks for women and five or more drinks for men are defined as binge drinking.

after the pregnancy became known, and if they had tried other drugs (Figure 2). A questionnaire was filled out after registration (baseline measurement). The same type of questionnaire was also filled out during week 33 of the pregnancy (post-measurement) (Figure 4).

The CG received information about the study in connection with the registration visit at the ANC-no information was sent home. The questionnaire was completed after the registration (baseline measurement) and another questionnaire in week 33 of the pregnancy (post-measurement) (Figure 4).

At the time of the study, the ANC record in Sweden contained two questions about alcohol use three months before pregnancy and at the time of the registration. The response alternatives were: once a month or less, once a week, or more often than once a week. Women were routinely given a booklet with general information about pregnancy and smoking, alcohol, food, etc. The record also contained two questions about alcohol use in week 33, which the midwife had to document in the patient record. This time-point, therefore, was chosen as being appropriate for the post-measurement.

The research instruments used in this study were AUDIT-C consisting of the first three items of AUDIT measuring quantity and frequency of alcohol consumption and frequency of heavy episodic drinking (Burns, Gray, \& Smith, 2010; Bush, Kivlahan, Mc Donell, Fihn, \& Bradley, 1998), together with a questionnaire containing some validated questions but used in a modified form (Thomas, 1994a, 1994b), and some questions developed for this study, since we could not find any questionnaire about social- and psychosocial support during pregnancy aimed at both partners (Figure 4). 


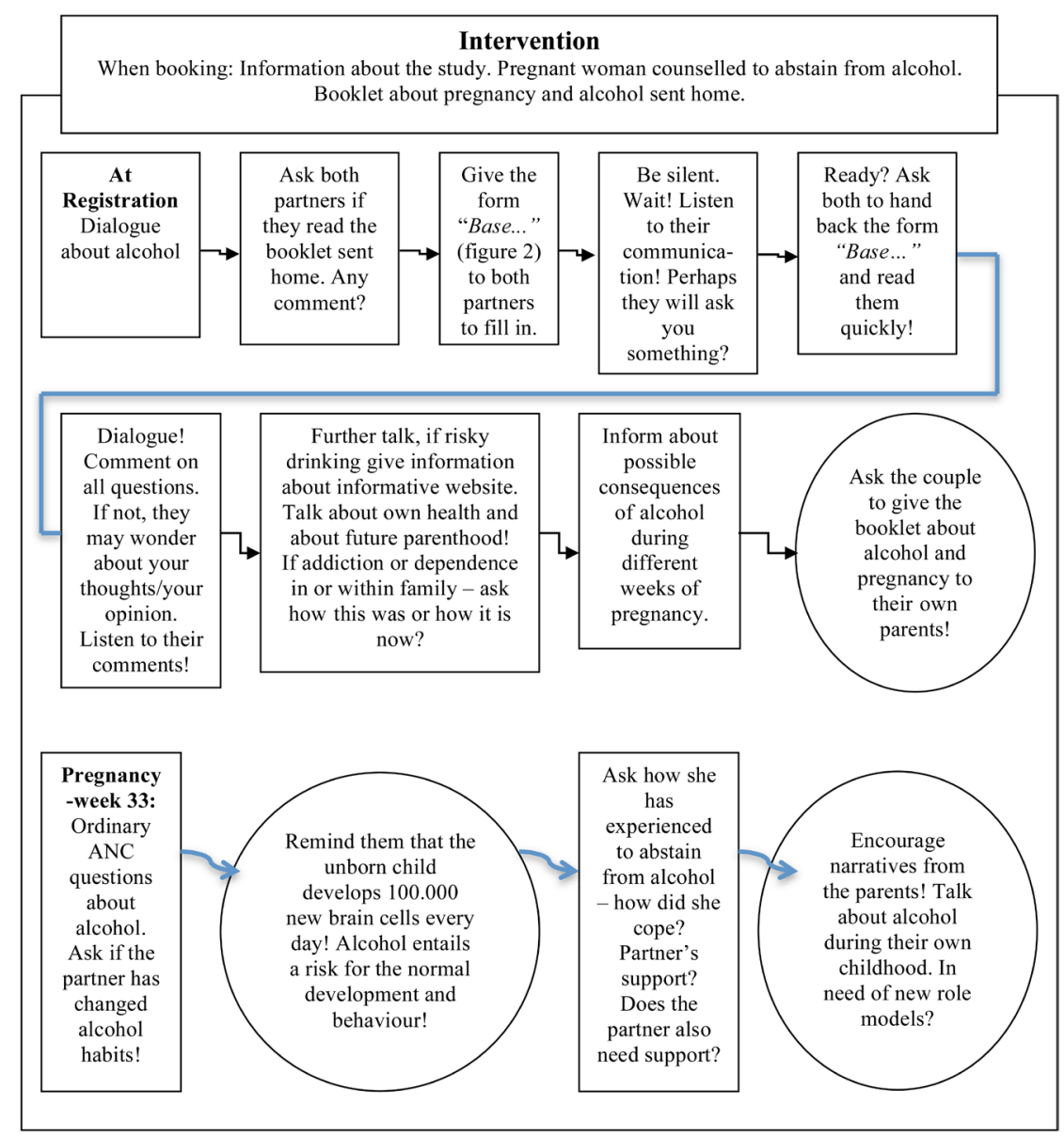

Figure 3. The intervention.

\begin{tabular}{|c|c|}
\hline Responders & Item \\
\hline $\begin{array}{l}\text { Woman and } \\
\text { partner }\end{array}$ & $\begin{array}{l}\text { Three AUDIT-C questions about alcohol consumption [Bush et al., 1998] and one question } \\
\text { about other drugs. One question about alcohol disorder in the family and three additional } \\
\text { questions about alcohol consumption (Figure } 2 \text { ). }\end{array}$ \\
\hline $\begin{array}{l}\text { Woman and } \\
\text { partner }\end{array}$ & $\begin{array}{l}\text { One open-ended question about how to manage a situation where alcohol would be } \\
\text { consumed. Four questions about activities to refrain from alcohol (yes/no). One question } \\
\text { about the difficulty in abstaining from alcohol (five-degree scale from very easy to very } \\
\text { difficult). Ten questions about social support (five-degree scale from always to never). Six } \\
\text { statements about support from partner with the response alternatives yes/no: Feels generally } \\
\text { positive but does not affect my behavior / Gives me the feeling that we are preparing for } \\
\text { parenthood and taking joint responsibility / Feels negative e.g., intrusive or annoying / No } \\
\text { importance whatsoever because I would not drink anything / Facilitates for me to say no to } \\
\text { alcohol. / I get no support for an alcohol-free pregnancy. }\end{array}$ \\
\hline $\begin{array}{l}\text { Woman and } \\
\text { partner }\end{array}$ & $\begin{array}{l}\text { Sixteen questions about how alcohol was used prior to pregnancy and during pregnancy } \\
\text { including reasons for, questions on concerns about one's own or a partner's alcohol } \\
\text { consumption, and thoughts about partner's concern about drinking alcohol consumption } \\
\text { (yes/no). Two questions allowed free comments. }\end{array}$ \\
\hline Woman & $\begin{array}{l}\text { Four questions about whether drinking during pregnancy causes worries and if she had talked } \\
\text { to someone about it (yes, no, don't know). }\end{array}$ \\
\hline $\begin{array}{l}\text { Woman and } \\
\text { partner }\end{array}$ & $\begin{array}{l}\text { Three questions about reactions to partner's use of alcohol (totally agree, partly agree, do not } \\
\text { agree). }\end{array}$ \\
\hline $\begin{array}{l}\text { Woman and } \\
\text { partner }\end{array}$ & $\begin{array}{l}\text { One question on information about alcohol during pregnancy (yes/no). Post-measurement } \\
\text { included three evaluation questions about new knowledge and influence on alcohol } \\
\text { consumption (five degree scale from not at all to very much) and who provided the most } \\
\text { important information (five degree scale, from most important to least important). }\end{array}$ \\
\hline
\end{tabular}

Figure 4. Description of the questionnaire. 


\subsection{Data Analysis}

SPSS 20.0 for Windows was used for data analysis. To examine the differences between the groups, we used Student's t-test for interval scaled data, Kruskal Wallis test for ordinal-scaled data, and Chi Square and Fishers exact tests for nominal scaled data. A difference was considered significant if $p<0.05$. To examine the potential confounders for the group differences in the variable offers alcohol-free alternatives, two binary logistic regression models were performed where we adjusted for age, education level, occupation, and previous children. The results are presented as Odds Ratios (OR) with 95\% confidence intervals (CI). Power was calculated assuming an intervention effect of $10 \%$ with $80 \%$ power.

\subsection{Ethics}

The Ethics Committee for Medical Research in Gothenburg and Lund/Malmö approved the study.

\section{Results}

Table 1 presents an overview of the participants in the two groups. The groups were similar, with only a few differences between the groups. The mean age of the pregnant women was 30.6 years and for expectant fathers 32.9 years. More partners (18\%) reported working more than full-time (40 hours/week) compared to pregnant women (5\%) at registration (baseline). In women's pregnancy week 33, two percent of the pregnant women and $17 \%$ of the partners in the IG and the CG still worked more than full-time (not shown in table).

Those who dropped out of the study only differed from those who remained in the study with respect to age. The participants who dropped out were slightly older (mean age 32.0) compared to those who remained in the study (mean age 31.2) $p=0.02$. There were no differences between the drop outs and those who remained in the study with respect to their education level, occupation, civil status, or if they had children or not.

\subsection{Use of Alcohol before and during Pregnancy}

About half of all the pregnant women (46.4\%) reported drinking alcohol during the current pregnancy before registration at the ANC. At registration most pregnant women (91.6\%) reported not drinking alcohol after pregnancy was announced, a few (2.5\%) drank as before, and the others had reduced their drinking (5.9\%) already upon registration at the ANC. In pregnancy week 33, less than $10 \%$ of the women reported drinking alcohol. Their male partners had a different pattern; only 6\% abstained from alcohol and about half of the men drank alcohol 2 - 4 times a month. No men reported that they had increased their alcohol consumption after pregnancy

Table 1. Characteristics of the participants in the groups.

\begin{tabular}{|c|c|c|c|c|c|}
\hline Variables & $\begin{array}{c}\text { IG } \\
\text { Women } \\
\%\end{array}$ & $\begin{array}{c}\text { CG } \\
\text { Women } \\
\%\end{array}$ & $\begin{array}{l}\text { IG } \\
\text { Men } \\
\%\end{array}$ & $\begin{array}{l}\text { CG } \\
\text { Men } \\
\%\end{array}$ & $\begin{array}{c}p \text {-value }{ }^{*} \\
\text { IG vs. } \mathrm{CG} \text { women/men }\end{array}$ \\
\hline Mean age & 30.8 & 30.4 & 33.3 & 32.5 & $0.30 / 0.80$ \\
\hline Living with partner & $\begin{array}{c}99.6 \\
n=253\end{array}$ & $\begin{array}{c}99.3 \\
n=286\end{array}$ & $\begin{array}{c}99.2 \\
n=255\end{array}$ & $\begin{array}{c}99.3 \\
n=280\end{array}$ & $1.00 / 1.00$ \\
\hline First time parent & $\begin{array}{c}39.6 \\
n=250\end{array}$ & $\begin{array}{c}41.1 \\
n=280\end{array}$ & $\begin{array}{c}36.3 \\
n=248\end{array}$ & $\begin{array}{c}41.7 \\
n=266\end{array}$ & $0.79 / 0.24$ \\
\hline Employed & 81.2 & 78.4 & 93.2 & 89.4 & \\
\hline Unemployed & 2.4 & 4.3 & 2.0 & 3.3 & \\
\hline Sick leave & 2.0 & 2.9 & 0.8 & 1.1 & $0.17 / 0.21$ \\
\hline \multirow[t]{2}{*}{ Other } & 14.4 & 14.4 & 4.0 & 6.2 & \\
\hline & $\mathrm{n}=250$ & $\mathrm{n}=278$ & $\mathrm{n}=249$ & $\mathrm{n}=275$ & \\
\hline Comprehensive school & 4.8 & 5.8 & 5.0 & 4.5 & \multirow{4}{*}{$0.84 / 0.89$} \\
\hline High school & 45.2 & 43.2 & 56.0 & 54.5 & \\
\hline \multirow[t]{2}{*}{ University } & 50.0 & 51.1 & 39.0 & 41.0 & \\
\hline & $\mathrm{n}=248$ & $\mathrm{n}=278$ & $\mathrm{n}=241$ & $\mathrm{n}=266$ & \\
\hline
\end{tabular}

\footnotetext{
*Differences between the groups tested with Student's t test, Fishers exact test, and Chi-square test.
} 
Table 2. Changes in alcohol consumption before pregnancy and in pregnancy week 33.

\begin{tabular}{|c|c|c|c|c|}
\hline & IG women & CG women & IG men & CG men \\
\hline Year before pregnancy & $\mathrm{n}=222(\%)$ & $\mathrm{n}=262(\%)$ & $\mathrm{n}=212(\%)$ & $\mathrm{n}=256(\%)$ \\
\hline More & $3(1.4)$ & $3(1.1)$ & $1(0.5)$ & $1(0.4)$ \\
\hline As earlier & $143(64.4)$ & $176(67.2)$ & $157(74.1)$ & $183(71.5)$ \\
\hline Less & $73(32.4)$ & $71(27.1)$ & $51(24.1)$ & $70(24.2)$ \\
\hline Teetotaler & $3(1.4)$ & $12(4.6)$ & $3(1.4)$ & $10(3.9)$ \\
\hline In week 33 & $\mathrm{n}=184(\%)$ & $\mathrm{n}=212(\%)$ & $\mathrm{n}=178(\%)$ & $\mathrm{n}=211(\%)$ \\
\hline More & $0(0.0)$ & $0(0.0)$ & $4(2.2)$ & $1(0.5)$ \\
\hline As earlier & $6(3.3)$ & $8(3.8)$ & $93(52.2)$ & $106(50.2)$ \\
\hline Less & $9(4.9)$ & $15(7.1)$ & $73(41.0)$ & $89(42.2)$ \\
\hline No alcohol at all & $169(91.8)$ & $189(89.2)$ & $8(4.5)$ & $15(7.1)$ \\
\hline
\end{tabular}

announcement, and $38 \%$ of the men stated that they had reduced their alcohol intake after the pregnancy was announced. In pregnancy week 33, only $2.2 \%$ of the partners had increased their alcohol use (Table 2).

A small proportion of all the pregnant women $6.8 \%(\mathrm{n}=38)$ continued to drink alcohol in early pregnancy (IG 6.7\%, CG 8.4\%) and in late pregnancy the corresponding number was $6.3 \%(n=35)$. A lower proportion of women who expected their first child compared to women who already had children continued to drink alcohol; IG $4.7 \%$ vs. CG $9.9 \%$ in early pregnancy $(p=0.05)$ and IG $5.3 \%$ vs. CG $11.5 \%$ in late pregnancy $(p=0.04)$.

The partners had a higher mean AUDIT-C (maximum 12 points, see Table 2, question 4 - 6) than the pregnant women, both at baseline, 6.71 vs. 5.46, $p<0.01$ and in pregnancy week 33, 6.27 vs. 2.22, $p<0.01$. The mean AUDIT-C at baseline did not differ between the women who continued to drink alcohol or not during pregnancy, but in pregnancy week 33 women who reported alcohol use during pregnancy had a higher mean AUDIT-C the year before pregnancy; 3.44 compared to 2.08 among women who stated that they did not drink alcohol during pregnancy. The partners' AUDIT-C points did not differ with respect to the women's use of alcohol during pregnancy, either at baseline or in pregnancy week 33. There was no difference in the mean AUDIT-C between the IG and the CG.

In week 33, 18\% of all fathers-to-be still reported a need to decrease their drinking before parenthood. Four percent of the pregnant women in the IG and $12.3 \%$ in the CG had at some point been worried about their own drinking. Less than three percent of the men had at some point been worried about the female partner's drinking. Eleven percent of the partners in the IG and 12.3\% in the CG reported that they had at some point been worried about their own alcohol consumption. Approximately 12\% (in both groups) of the pregnant women had at some point been worried about their partner's alcohol consumption.

\subsection{Binge Drinking and Stress Relief}

More than one in four women and more than one in three men used alcohol to get drunk before pregnancy. About one in five women and more than one in four men used alcohol as stress relief before pregnancy. The post-measurement in pregnancy-week 33 showed that one pregnant woman reported binge drinking during pregnancy. Of the partners, $27 \%$ of the IG and $29 \%$ of the CG continued binge drinking. In the post-measurement, $17 \%$ of the IG and $21 \%$ of the CG partners reported binge drinking as "normal consumption" during pregnancy. Two pregnant women and more than one in four partners reported stress relief drinking also during the pregnancy period. No significant differences between groups.

\subsection{Alcoholism in the Family/among Relatives}

More than three out of four of both women and men were not aware of any alcoholism in their own family, but $25 \%$ of the pregnant women and $20 \%$ of the partners reported alcoholism in their family, and in this group between six (CG) and twelve percent (IG) reported a mother or a father with alcoholism. In nine percent of all the 
couples, both partners reported alcoholism in the family; altogether 35\% of the couples reported any experience of alcoholism in either of the families. Partners, who reported alcoholism in their own family, had a higher mean AUDIT-C than partners without this experience; 7.72 vs. $6.68, p<0.01$.

\subsection{Support for an Alcohol-Free Pregnancy}

Most women (92\%) in both the groups stated that the partner's support to give up alcohol was important. When asked what it means for a pregnant woman to receive support from a partner to give up alcohol during pregnancy and what it means for fathers-to-be to get support from their partner to reduce alcohol before parenthood, four out of five pregnant women and three out of four fathers-to-be reported that the support from the partner resulted in "a feeling that we are teaming up for parenthood and taking joint responsibility." A larger proportion of the women who abstained from alcohol during pregnancy, compared to those who continued to drink alcohol, agreed to the statement that the partner's support for an alcohol-free pregnancy was important; 94.2\% vs. 79.5\% $(p<0.01)$. Many partners in both groups supported the pregnant women by never or seldom drinking alcohol with her, $75 \%$ in the IG compared to $67 \%$ in the CG.

Two thirds (68.4\%) of the pregnant women who continued to drink during pregnancy reported that their partners “always offered alcohol-free alternative” compared with $82.4 \%$ of pregnant women who did not drink alcohol during pregnancy, $p=0.049$. At post-measurement, the women in the IG were more often offered alcoholfree alternatives compared with the women in the CG $(p=0.002)$. We performed two binary logistic regression models to control for potential confounding variables in relation to the dependent variable always offers alcoholfree alternatives and found that for women, older age (OR 1.11) and having received the intervention (OR 2.13) were associated with having been offered alcohol-free alternatives. So was also, for men, having previous children (OR 1.68) (Table 3).

\subsection{Support from Parents and Others in Changing Alcohol Consumption during Pregnancy}

In week 33, most pregnant women (90\%) reported “always” receiving support to abstain from alcohol from their own mother, compared to $44 \%$ of the fathers-to-be. Eight percent among pregnant women and $40 \%$ of fathers-to-be never had experienced this support from their mother. In week 33, most pregnant women (89\%) reported “always” receiving support to abstain from alcohol from their own father, compared to $41 \%$ of the fathers-to-be. Eight percent among pregnant women and 42\% of fathers-to-be reported “never” having received such support. In week 33, four out of five pregnant women reported "always" receiving support to abstain from alcohol from others, but only $35 \%$ of the fathers-to-be reported always being supported to reduce or abstain from alcohol consumption. Eight percent among pregnant women and $42 \%$ of fathers-to-be never got this support.

\subsection{Sources of Information about Alcohol and Pregnancy}

Sixty-eight percent of the IG women and 54.1\% of the IG partners stated that they had received the most important information from the ANC during this or an earlier pregnancy (Table 4). Fifty-two percent of the CG women and $49.0 \%$ of the CG partners stated that they had received the most important information from the ANC. There was a difference between the groups, however, when the data was split for men and women; the

Table 3. Adjusted odds ratios and 95\% confidence intervals for offering alcohol free alternative.

\begin{tabular}{|c|c|c|}
\hline Offers alcohol free alternatives "always" & Women & Men \\
\hline Variables & OR $(95 \%$ CI $)$ & OR (95\% CI) \\
\hline Age (year) & $1.11(1.03-1.18)$ & $1.03(0.98-1.08)$ \\
\hline Education level (low vs. high) & $1.73(0.99-3.00)$ & $0.94(0.57-1.53)$ \\
\hline Occupation (other occupation vs. working) & $1.17(0.63-2.17)$ & $2.25(0.91-5.56)$ \\
\hline No previous children vs. previous children & $1.46(0.85-2.57)$ & $1.68(1.02-2.76)$ \\
\hline Group (CG vs. IG) & $2.13(1.29-3.51)$ & $1.59(0.99-2.55)$ \\
\hline
\end{tabular}


Table 4. Most important sources of information about alcohol and pregnancy.

\begin{tabular}{|c|c|c|c|c|}
\hline Most important source of information & $\begin{array}{c}\text { IG Women } \\
\text { n (\%) }\end{array}$ & $\begin{array}{c}\text { CG Women } \\
\text { n (\%) }\end{array}$ & $\begin{array}{l}\text { IG Men } \\
\text { n (\%) }\end{array}$ & $\begin{array}{c}\text { CG Men } \\
\text { n (\%) }\end{array}$ \\
\hline Dialogue with midwife during this pregnancy & $\begin{array}{c}34(21.8) \\
n=156\end{array}$ & $\begin{array}{c}22(13.7) \\
n=161\end{array}$ & $\begin{array}{c}27(20.3) \\
n=133\end{array}$ & $\begin{array}{c}24(15.5) \\
n=155\end{array}$ \\
\hline Booklet from ANC during this pregnancy & $\begin{array}{c}33(20.2) \\
n=163\end{array}$ & $\begin{array}{c}28(17.4) \\
n=161\end{array}$ & $\begin{array}{c}16(11.3) \\
n=155\end{array}$ & $\begin{array}{l}15(9.7) \\
n=155\end{array}$ \\
\hline Media & $\begin{array}{c}34(20.6) \\
n=165\end{array}$ & $\begin{array}{c}76(42.0) \\
n=181\end{array}$ & $\begin{array}{c}61(42.1) \\
n=145\end{array}$ & $\begin{array}{c}78(44.1) \\
n=177\end{array}$ \\
\hline Family or friends & $\begin{array}{l}13(8.7) \\
n=150\end{array}$ & $\begin{array}{l}12(7.7) \\
n=155\end{array}$ & $\begin{array}{c}7(5.4) \\
\mathrm{n}=129\end{array}$ & $\begin{array}{c}19(11.7) \\
n=163\end{array}$ \\
\hline ANC during earlier pregnancy & $\begin{array}{c}38(26.0) \\
n=146\end{array}$ & $\begin{array}{c}31(21.1) \\
n=147\end{array}$ & $\begin{array}{c}29(22.5) \\
n=129\end{array}$ & $\begin{array}{c}34(23.8) \\
n=143\end{array}$ \\
\hline $\begin{array}{c}\text { In total, from } \\
\text { ANC (Dialogue, booklet, and earlier pregnancy) }\end{array}$ & $68.0^{*}$ & $52.2^{*}$ & 54.1 & 49.0 \\
\hline
\end{tabular}

${ }^{*}$ Chi-square test of differences between the groups among women $p=0.001$, among men $p=0.447$, and among all participants $p=0.002$.

difference was only shown among women.

\section{Discussion}

About half of the pregnant women reported drinking alcohol during pregnancy before registration at the ANC; however, after the pregnancy was confirmed most women did not drink alcohol. This could mean that pregnant women in our study had good knowledge about alcohol and pregnancy. However, a few of the pregnant women continued to drink, and among them a higher proportion already had children. One possible explanation could be that these mothers had experienced having a healthy child in spite of their alcohol consumption during an earlier pregnancy. This implies that equal or even more attention should be paid to the parents who already have children. A dissertation in Sweden showed that 30\% (in 1999) and 16\% (in 2004) of women in the capital city continued drinking alcohol during pregnancy (Göransson, 2004). Pregnant women may feel reluctant to admit alcohol consumption in general, and excessive consumption in particular and therefore be uneasy about clarifying their needs of support for an alcohol-free pregnancy.

In both groups, pregnant women stated that the father-to-be supported her in giving up alcohol during pregnancy by not drinking together with her. After the intervention, more women in the IG stated that they were offered alcohol-free drinks compared with the CG. Thus, the dialogue with the midwife may have promoted an awareness that facilitated for the fathers-to-be to support their pregnant partner.

One-fifth of the fathers-to-be stated toward the end of the pregnancy, that they felt a need to reduce alcohol consumption. This may reflect that fathers-to-be received weaker support than the pregnant women for changing their drinking during pregnancy, and only around $35 \%$ - 44\% of fathers-to-be reported that they always got support from their own mother, father, or others. Furthermore, they also reported to a lower degree that ANC gave them the most important information on alcohol and parenthood, in comparison with the pregnant women. Not all fathers-to-be participated in the registration visits at the ANC, even though this has become more common over the last few decades in Sweden. Early pregnancy is an excellent time and gives a natural opportunity to reach fathers-to-be/partners and to provide health promotion regarding alcohol in a lifecycle perspective. Pregnancy is a transition in life and typically involves reflection and reorientation of values, habits, and life plans on the way toward parenthood. First time parents are generally motivated to make lifestyle changes. The couples reported getting support from their partner to reduce alcohol before parenthood, and a majority felt that they were "teaming up for parenthood and taking joint responsibility." This motivation can serve as a basis for the midwife's dialogues about alcohol, e.g. to encourage mutual support within all couples.

Every third couple had some personal experience of Alcohol Disorder within their own family and about ten percent had at least one parent with Alcohol Disorder. The issue of heredity for Alcohol Disorder is therefore relevant to discuss. Alcohol consumption of the fathers-to-be/partners should also be discussed during antenatal counseling to raise awareness about the relationship between risky drinking and Alcohol Disorder. More than ten percent of women reported that they had been worried about the partner's alcohol consumption. 
After the intervention, more pregnant women in the IG stated that the ANC was the best source of information about alcohol, pregnancy, and parenthood, indicating that such a dialogue was both accepted and appreciated by the women. Drinking patterns can certainly be changed without professional support, but in combination with the surrounding social and psychosocial support for an alcohol-free pregnancy a dialogue on alcohol drinking provides a good possibility for avoiding unborn children being exposed to alcohol. The dialogue in early pregnancy on alcohol may from a life cycle perspective comprise three or four generations: grandparents, own parents, the pregnant woman and partner, the fetus or unborn child and their siblings.

The midwife's dialogue about alcohol from a life cycle perspective with parents-to-be is complex and we were only able to demonstrate a few effects of the intervention. There is a need for increased knowledge about methodology, optimal structure within the ANC organization, and policy decisions to implement this public health work in practice. The midwives meet the vast majority of pregnant women ( $>98 \%$ in Sweden) and can also meet most fathers-to-be/partners. The midwife could then initiate a dialogue about alcohol with the couple that can be followed up later, since repeated counseling is likely to be more effective than one single session. Previous studies show that conversations about alcohol, intimate domestic violence (Edin, 2002), and other psychosocial difficulties (Dejin-Karlsson, 1999; Flynn, Walton, Chermack, Cunningham, \& Marcus, 2007) should be undertaken before the child is born. Future studies should follow up on the situation in the family to investigate if the changed pattern of alcohol use is stable after pregnancy. Reflections on parenthood and alcohol could be continued within child health services, in preschool, in elementary school, and in parent education during the child's upbringing.

\subsection{Limitations}

One weakness in this study was that we not were able to conduct a randomized controlled trial. However, only a few differences were found between the groups at baseline. Further, only Swedish-speaking parents-to-be were included; thus, generalized conclusions have to be restricted to this population. We did not find any research tools on dialogue about drinking and attitudes toward alcohol during pregnancy with both parents-to-be (Burns et al., 2010; Skagerstrom et al., 2011). We did not find many published articles with interventions based on dialogues with both parents during pregnancy, nor even a tool that measured the social- and psychosocial support or instruments indicating the importance of social- and psychosocial support for an alcohol-free pregnancy with both parents-to-be. The Spouse Enabling Inventory (Thomas, 1994a) and the Spouse Sobriety Influence Inventory (Thomas, 1994b) were used in a modified form and worked well, but more studies are needed to confirm the usefulness and the validity of the instrument during pregnancy.

\subsection{Conclusion}

After the intervention, a higher proportion of the women in the IG were offered alcohol-free alternatives, and among women the ANC was the most important source of information about alcohol. Alcohol consumption was low among all pregnant women in late pregnancy and about $40 \%$ of the partners had reduced their alcohol consumption, indicating that pregnancy was a crucial moment for changing patterns of alcohol intake. Involving the partner in counseling about alcohol restriction during pregnancy may be a useful health promotion strategy and all parents-to-be should be given the opportunity to talk about the use of alcohol in a life cycle perspective.

\section{References}

Aaronson, L. S. (1989). Perceived and Received Support: Effects on Health Behaviour during Pregnancy. Nursing Research, 38, 4-9.

Abela, M. B. (2000). Factors Associated with Alcohol Consumption: From a Developmental Perspective. Doctoral Dissertation.

Austin, M. P., Priest, S. R., \& Sullivan, E. A. (2008). Antenatal Psychosocial Assessment for Reducing Perinatal Mental Health Morbidity. Cochrane Database of Systematic Reviews, 4, Article ID: CD005124. http://dx.doi.org/10.1002/14651858.CD005124.pub2

Black, D., Cobben, J., Didden, R., Lindhout, D., Pereira, R., \& van Wieringen, H. (2007). Low Levels of Prenatal Alcohol Exposure Can Cause Fetal Damage. British Journal of Obstetrics and Gynaecology, 114, 778-779. http://dx.doi.org/10.1111/j.1471-0528.2007.01352.x

Boyce, P., Condon, J., Barton, J., \& Corkindale, C. (2007). First-Time Fathers’ Study: Psychological Distress in Expectant 
Fathers during Pregnancy. Australian and New Zealand Journal of Psychiatry, 41, 718-725. http://dx.doi.org/10.1080/00048670701517959

Burns, E., Gray, R., \& Smith, L. A. (2010). Brief Screening Questionnaires to Identify Problem Drinking during Pregnancy: A Systematic Review. Addiction, 105, 601-614. http://dx.doi.org/10.1111/j.1360-0443.2009.02842.x

Bush, K., Kivlahan, D. R., McDonell, M. B., Fihn, S. D., \& Bradley, K. A. (1998). The AUDIT Alcohol Consumption Questions (AUDIT-C): An Effective Brief Screening Test for Problem Drinking. Ambulatory Care Quality Improvement Project (ACQUIP). Alcohol Use Disorders Identification Test. Archives of Internal Medicine, 158, 1789-1795. http://dx.doi.org/10.1001/archinte.158.16.1789

CAN (2014). Drug Development. Stockholm. http://can.se/sv/Rapporter/Drogutvecklingen-i-Sverige-2011/

Chang, G., McNamara, T. K., Orav, E. J. O., \& Wilkins-Haug, L. (2006). Brief Intervention for Prenatal Alcohol Use: The Role of Drinking Goal Selection. Journal of Substance Abuse Treatment, 31, 419-424. http://dx.doi.org/10.1016/j.jsat.2006.05.016

Chang, G., Wilkins-Haug, L., Berman, S., \& Goetz, M. A. (1999). Brief Intervention for Alcohol Use in Pregnancy: A Randomized Trial. Addiction, 94, 1499-1508. http://dx.doi.org/10.1046/j.1360-0443.1999.941014996.X

Coles, C. D., Goldstein, F. C., Lynch, M. E., Chen, X., Kable, J. A., Johnson, K. C., \& Hu, X. (2011). Memory and Brain Volume in Adults Prenatally Exposed to Alcohol. Brain and Cognition, 75, 67-77. http://dx.doi.org/10.1016/j.bandc.2010.08.013

Day, N. L., Helsel, A., Sonon, K., \& Goldschmidt, L. (2013). The Association between Prenatal Alcohol Exposure and Behavior at 22 Years of Age. Alcoholism: Clinical and Experimental Research, 37, 1171-1178. http://dx.doi.org/10.1111/acer.12073

Dejin-Karlsson, E. (1999). Psychosocial Resources, Life-Style Factors and Fetal Growth. With Special Reference to Smallfor-Gestational Age (SGA) Infants. M.D. Thesis, Lund: Lund University.

Dunkel-Schetter, C., Sagrestano, L. M., Feldman, P., \& Killingsworth, C. (1996). Social Support and Pregnancy. A Comprehensive Review Focusing on Ethnicity and Culture. In G. R. Pierce, B. R. Sarason, \& I. G. Sarason (Eds.), Handbook of Social Support and the Family (pp. 375-412). New York: Plenum Press. http://dx.doi.org/10.1007/978-1-4899-1388-3_16

Edin, K. E., \& Högberg, U. (2002). Violence against Pregnant Women Will Remain Hidden as Long as No Direct Questions Are Asked. Midwifery, 18, 268-278. http://dx.doi.org/10.1054/midw.2002.0318

Flynn, H. A., Walton, M. A., Chermack, S. T., Cunningham, R. M., \& Marcus, S. M. (2007). Brief Detection and Co-Occurrence of Violence, Depression and Alcohol Risk in Prenatal Care Settings. Archives of Women's Mental Health, 10, 155161. http://dx.doi.org/10.1007/s00737-007-0188-6

Genesoni, L., \& Tallandini, M. A. (2009). Men’s Psychological Transition to Fatherhood: An Analysis of the Literature, 1989-2008. Birth, 36, 305-318. http://dx.doi.org/10.1111/j.1523-536X.2009.00358.x

Göransson, M. (2004). Alcohol Consumption during Pregnancy: How Do We Separate Myth from Reality? MD. Thesis, Stockholm: University Karolinska Institutet. http://diss.kib.ki.se/2004/91-7140-136-9

Harrison, P. A., Godecker, A., \& Sidebottom, A. C. (2011). Psychosocial Risk Screening during Pregnancy: Additional Risks Identified during a Second Interview. Journal of Health Care for the Poor and Underserved, 22, 1344-1357. http://dx.doi.org/10.1353/hpu.2011.0122

Henderson, J., Gray, R., \& Brocklehurst, P. (2007). Systematic Review of Effects of Low-Moderate Prenatal Alcohol Exposure on Pregnancy Outcome. BJOG: An International Journal of Obstetrics \& Gynaecology, 114, 243-252. http://dx.doi.org/10.1111/j.1471-0528.2006.01163.x

Holmqvist, M., \& Nilsen, P. (2010). Approaches to Assessment of Alcohol Intake during Pregnancy in Swedish Maternity Care-A National-Based Investigation into Midwives’ Alcohol-Related Education, Knowledge and Practice. Midwifery, 26, 430-434. http://dx.doi.org/10.1016/j.midw.2008.10.009

Hyssälä, L., Rautava, P., \& Sillanpää, M. (1992). Health Behaviour of Fathers of Young Families Expecting Their First Baby. Scandinavian Journal of Social Medicine, 20, 165-172.

Jones, K. L., \& Smith, D. W. (1973). Recognition of the Fetal Alcohol Syndrome in Early Infancy. The Lancet, 302, 9991001. http://dx.doi.org/10.1016/S0140-6736(73)91092-1

Mellingen, S., Torsheim, T., \& Thuen, F. (2013). Changes in Alcohol Use and Relationship Satisfaction in Norwegian Couples during Pregnancy. Substance Abuse Treatment Prevention and Policy, 8, 5. http://dx.doi.org/10.1186/1747-597X-8-5

Ogden, J. (2000). Stress Health Psychology: A Textbook (pp. 231-254). Buckingham; Philadelphia, PA: Open University Press. 
Saunders, J. B., Aasland, O. C., Babor, T. F., De la Fuente, J. R., \& Grant, M. (1993). Development of the Alcohol Use Disorders Identification Test. (AUDIT): WHO Collaborative Project on Early Detection of Persons with Harmful Alcohol Consumption-II. Addiction, 88, 791-804. http://dx.doi.org/10.1111/j.1360-0443.1993.tb02093.x

Sayal, K. (2007). Alcohol Consumption in Pregnancy as a Risk Factor for Later Mental Health Problems. Evidence Based Mental Health, 10, 98-100. http://dx.doi.org/10.1136/ebmh.10.4.98-a

Skagerstrom, J., Chang, G., \& Nilsen, P. (2011). Predictors of Drinking during Pregnancy: A Systematic Review. Journal of Women's Health (Larchmt), 20, 901-913. http://dx.doi.org/10.1089/jwh.2010.2216

Skagerström, J., Johansson, A. L., Holmqvist, M., Envall, E. K., \& Nilsen, P. (2012). Towards Improved Alcohol Prevention in Swedish Antenatal Care? Midwifery, 28, 314-320. http://dx.doi.org/10.1016/j.midw.2011.04.008

Sullivan, P. F., Daly, M. J., \& O’Donovan, M. (2012). Genetic Architectures of Psychiatric Disorders: The Emerging Picture and Its Implications. Nature Reviews Genetics, 13, 537-551. http://dx.doi.org/10.1038/nrg3240

Thomas, E. J., Yoshioka, M. R., \& Ager, R. D. (1994a). Spouse Enabling Inventory (SEI). Handbook of Family Measurement Techniques, 3, 252.

Thomas, E. J., Yoshioka, M. R., \& Ager, R. D. (1994b). Spouse Sobriety Influence Inventory (SSII). Handbook of Family Measurement Techniques, 3, 253.

van der Wulp, N. Y., Hoving, C., \& de Vries, H. (2014). Partner’s Influences and Other Correlates of Prenatal Alcohol Use. Maternal and Child Health Journal. http://dx.doi.org/10.1007/s10995-014-1592-y

Weitzman, E. R., \& Wechsler, H. (2000). Alcohol Use, Abuse, and Related Problems among Children of Problem Drinkers: Findings from a National Survey of College Alcohol Use. Journal of Nervous \& Mental Disease, 188, 148-154. http://dx.doi.org/10.1097/00005053-200003000-00004

World Health Organization. Regional Office for Europe (2012). European Action Plan to Reduce the Harmful Use of Alcohol 2012-2020. Copenhagen: WHO Regional Office for Europe. 